\title{
ANÁLISE DA COMPETITIVIDADE SISTÊMICA DA INDÚSTRIA DE MADEIRA NO ESTADO DO PARÁ
}

\author{
Antônio Cordeiro de Santana ${ }^{l}$
}

\begin{abstract}
Resumo - A competitividade da indústria de madeira beneficiada foi analisada à luz dos seguintes modelos teóricos: estrutura-conduta-desempenho, forças competitivas de Porter e competitividade sistêmica. Evidencia-se uma gama de produtos diversificados e diferenciados que estão sendo fabricados e fornecidos aos mercados locais, regionais, nacional e internacional. Avaliaram-se o processo de reestruturação competitiva da indústria de madeira, que alterou o processo de gestão, e a dinâmica de produção e do sistema de governança nas cadeias produtivas de madeira, artefatos, laminados e compensados e móveis, em razão da legislação ambiental e da pressão do mercado consumidor por qualidade, diferenciação de produto e sustentabilidade social e ambiental. A ação das forças competitivas que estão induzindo às mudanças nas estratégias de negócio resultou em perda de competitividade, com queda de $13,62 \%$ no market share das empresas de madeira serrada e beneficiada, de 1995 a 2001. O ideário atual é focar o cliente, diferenciar e diversificar a produção, dentro de uma mesma planta ou em combinação com outras plantas, com vistas em agregar valor aos produtos e obter economia de escala, de escopo e de aglomeração.
\end{abstract}

Palavras-chave: Empresas de madeira, competitividade sistêmica, cadeia produtiva, mercado.

\section{Introdução}

A indústria de madeira do Estado no Pará é constituída das empresas de madeira beneficiada (tábua, pranchas, caibro, ripa e barrotes de madeira), madeira laminada (lâminas de madeira com várias espessuras e bitolas), compensado de madeira (madeirite, compensado, aglomerado, placas), artefatos (esquadrias, lambris, assoalhos, portas, janelas, pernas-mancas, molduras para quadros, decks de piscina, brinquedos e utilidades de cozinha), móveis e produtos finais (Santana, 2002). Nessas

\footnotetext{
${ }^{1}$ D. Sc. em Economia Rural e Professor da Universidade Federal Rural da Amazônia - UFRA. E-mail: santana@nautilus.com.br.

Recebido em 29/04/2003 - Aceito em 30/05/2003
} 
empresas, a qualidade do produto, assim como sua diferenciação, ocorre de acordo com o destino dos produtos finais. Atualmente, as empresas de madeira serrada e beneficiada também estão fabricando móveis e artefatos, na mesma fábrica ou em unidades separadas da mesma empresa. A agregação de valor está se transformando no vetor de alterações na estrutura das empresas e nas estratégias para criar vantagens competitivas e assegurar o desempenho.

Por um lado, muitas dessas empresas produzem apenas para o mercado local e regional dos pólos produtores de Belém e Ananindeua, Breves, Marabá, Paragominas e Santarém, nos quais o produto apresenta baixa qualidade. Por outro, é considerável o número de empresas de madeira beneficiada que exportam para as regiões Nordeste, Sudeste e Sul e para o mercado internacional. Todas essas empresas são formais e muitas delas empregam tecnologia moderna, normas técnicas de produto e de processo e qualificação de mão-de-obra, e o produto, além de diferenciado, apresenta alto padrão de qualidade (Santana, 2002).

A questão é o processo, em curso, de reestruturação competitiva da indústria madeireira no Estado do Pará, dada a legislação ambiental que afetou, drasticamente, as formas de manejo da floresta e de acesso à matéria-prima e dadas as exigências internacionais com produtos de qualidade. Observa-se evolução na diversificação da pauta de exportação de produtos madeireiros, ao mesmo tempo que a indústria madeireira incorpora maior densidade tecnológica. No âmbito interno da indústria, nota-se uma reestruturação que vai da adequação de escala, passa pela implementação de processo novo, até a fabricação de produtos de maior valor agregado à implementação de manejo florestal.

O conceito de competitividade sistêmica é aplicado na análise da rede de conexões que as empresas de madeira beneficiada estabelecem com os fornecedores de matéria-prima, com os clientes e com toda a dinâmica das cadeias de negócios da madeira, abrangendo fatores estruturais, tecnológicos, socioeconômicos, de regulamentação e institucionais, que influenciam o desempenho competitivo das empresas participantes da indústria madeireira. 
Além dos fatores internos das empresas, o estudo evidencia a relação das empresas de madeira serrada e beneficiada com os fornecedores (extratores de madeira, pecuaristas, agricultores, indústrias de insumos, máquinas e ferramentas), com os clientes (estâncias, marcenarias, movelarias, comércio, construção civil, governo, famílias), e com as instituições (governamentais, não-governamentais), o que permite identificar como a legislação ambiental, o custo do frete, a infra-estrutura de estradas e transporte, a carga de tributos, os serviços financeiros, os serviços de aduaneira e os preços estão influenciando o desempenho das empresas.

O objetivo deste trabalho foi identificar e analisar os fatores competitivos que influem na competitividade sistêmica das empresas de madeira beneficiada, o que será feito por meio de diagnóstico das características, condições, estrutura e prospecção dos mercados domésticos (local, regional e nacional) e internacional das empresas de madeira do Estado do Pará.

\section{Metodologia}

\subsection{Modelo conceitual}

O estudo da competitividade trata da avaliação dos ambientes de ameaças e de oportunidades das empresas, tendo em vista a formação de estratégias competitivas sustentáveis. Esses ambientes envolvem os fatores determinantes da estrutura industrial, da conduta e do desempenho sustentável das empresas. A importância fundamental da análise dos ambientes de ameaça e de oportunidade das empresas de uma indústria está na avaliação do grau de sua atratividade econômica global. Essa atratividade é determinada pelo desempenho médio das empresas na economia, ou seja, empresas que apresentam baixas ameaças e alta oportunidade em relação ao conjunto de empresas concorrentes e, ou, rivais. 
Apresentam-se os instrumentais teóricos que envolvem três modelos de análise que representam a evolução do conhecimento sobre organização e evolução industrial, desenvolvidos a partir de meados do século passado. Inicia-se com o modelo Estrutura-Conduta-Desempenho-ECD, de Mason (1939) e Bain (1968); em seguida, apresenta-se o modelo das forças competitivas de Porter - FCP (Porter, 1990); depois, apresenta-se o modelo da competitividade sistêmica, da OCDE (1992) e de Coutinho e Ferraz (1994). Ao final, faz-se uma integração geral dos três modelos, como forma adequada para avaliar o ambiente competitivo das empresas de madeira beneficiada.

\subsubsection{O modelo estrutura-conduta-desempenho - ECD}

A análise das relações entre as empresas e de seu ambiente competitivo (estrutura, formação de estratégias e desempenho) iniciou-se nos anos 30, com Mason (1939), e depois foi aprofundada por Bain (1968) (Possas, 1987; Ferguson e Ferguson, 1994; Barney, 1996; Shy, 1997). A idéia fundamental do modelo $\boldsymbol{E} \boldsymbol{C D}$ é descrever as condições em que a dinâmica da estrutura de mercado, ao interagir com a formação de estratégias de negócios, com as regulamentações do governo e com os demais fatores que influenciam o desempenho das empresas, pode-se transformar em ameaças, e como criar oportunidades competitivas a partir disso.

A estrutura teórica desenvolvida, que tornou amplamente conhecido o modelo $\boldsymbol{E} \boldsymbol{C D}$, contempla um conjunto de fatores, organizados em três dimensões e articulados por uma ordem causal em que a estrutura industrial determina a conduta das empresas e esta, por sua vez, influencia o desempenho das empresas.

A Estrutura - $\boldsymbol{E}$ diz respeito à indústria, suas características e composição do mercado, sendo dimensionada por meio de fatores, como número de fornecedores e de clientes (oferta e demanda) e suas relações, diferenciação dos produtos, barreiras à entrada e à saída, estrutura de custos (economias de escala, de escopo e de aglomeração) e integração vertical. 
A Conduta - $\boldsymbol{C}$ refere-se às ações das empresas de uma indústria no mercado, incluindo a formação e comportamento dos preços, a estratégia de produtos (engenharia de design, orientação do produto para nichos de mercado, padrão de qualidade, etc.), a diversidade de produto, pesquisa e desenvolvimento (desenvolvimento de inovações tecnológicas em produtos, processos e serviços), o estabelecimento de uma governança (formar alianças verticais, coordenar cadeias produtivas, orientar a organização da produção) e a política de gastos em marketing, aquisição de equipamentos e redimensionamento da planta.

O Desempenho - $\boldsymbol{D}$ é avaliado em três direções: o desempenho das empresas na indústria e em relação à economia como um todo, considerando-se os mercados locais, nacional e internacional.

As linkages entre as estruturas do modelo $\boldsymbol{E C D}$ foram, inicialmente, estabelecidas de forma unidirecional, cabendo à estrutura industrial em que a empresa opera a definição do leque de opções e restrições que a afetam. Na indústria madeireira do Estado do Pará, as microempresas e as pequenas empresas de madeira serrada e beneficiada operam em regime de concorrência pura, sendo tomadoras de preços. Há, também, empresas que operam em regime de oligopólio (médias e grandes empresas de laminado e compensado, empresas exportadoras de madeira beneficiada) e empresas que operam em regime de monopólio, como é o caso de uma grande empresa de utilidades de cozinha.

Assim, o desempenho (lucro, market share) resulta sempre da estrutura industrial e da conduta das empresas. Os resultados de muitos estudos e a prática mostraram que a causalidade do modelo não flui de forma unidirecional, de modo que, diante do ambiente de ameaças, a causalidade pode seguir em ambas as direções. Uma empresa pode determinar uma política de inovações tecnológicas que determina a diferenciação de produtos e cria novas barreiras à entrada, assim como pode alterar a estrutura de custos. Nesse caso, a conduta determina a estrutura, gerando uma causalidade bidirecional. Da mesma forma, a identificação de uma queda na rentabilidade da empresa pode induzir a mudanças na 
conduta e na estrutura da empresa, forçando novas formas de organização e formação de alianças verticais.

Embora se reconheça que as dimensões do modelo $\boldsymbol{E} \boldsymbol{C D}$ interagem entre si, não é possível uma avaliação precisa e completa dos efeitos dinâmicos, produzidos pelas regulamentações governamentais e pelas políticas macroeconômicas, comerciais e reguladoras que influenciam a indústria e as empresas. Em virtude disso, Porter (1990) redimensionou o foco da análise e criou o modelo do diamante competitivo, mais apropriado para avaliar as vantagens competitivas sustentáveis das empresas.

\subsubsection{O modelo híbrido da competitividade de Porter}

O modelo de Porter (1990) apóia-se nas forças que configuram o ambiente de ameaças das empresas. Na verdade, o modelo pauta-se na eleição de alguns fatores determinantes da estrutura e da conduta do modelo $\boldsymbol{E} \boldsymbol{C D}$, articulados de forma dinâmica e interagindo simultaneamente, para determinar o desempenho das empresas. Esses fatores constituem as cinco forças competitivas de Porter - FCP: barreiras à entrada, rivalidade e produtos substitutos, condições de fatores/poder dos fornecedores e condições de demanda/poder dos clientes. Essas forças atuam, como ameaça, no desempenho da indústria e, por conseqüência, nas empresas.

Segundo Porter (1990), essas cinco forças da estrutura industrial podem ameaçar a sustentabilidade do desempenho industrial. Assim, esse conjunto de forças pode ser avaliado como uma ameaça, e, a partir de sua identificação, pode-se construir uma matriz de oportunidades para a empresa.

Barreira à entrada: A primeira força ameaçadora da indústria é a barreira à entrada de novas empresas na indústria, que, de acordo com o modelo $\boldsymbol{E} \boldsymbol{C D}$, é estimulada pela obtenção de lucros acima do normal. Se as empresas pertencentes à indústria madeireira, por exemplo, estão obtendo elevado desempenho e as barreiras à entrada nessa indústria 
são frágeis, muitas outras empresas, inclusive de outras indústrias, podem concretizar seus desejos de entrar na indústria de madeira. Entretanto, cada indústria oferece várias dificuldades à entrada de novas empresas no negócio, entre elas, as economias de escala, a diferenciação de produtos, a vantagem de custos e a regulamentação governamental.

A diferenciação de produto funciona como uma barreira à entrada, porque as empresas concorrentes têm de absorver os custos associados ao início da produção e à estratégia adotada para superar as vantagens da diferenciação do produto. Outras vantagens de que a empresa pode dispor para enfrentar as ameaças à entrada são as vantagens de custos criadas pela propriedade tecnológica (patente), pelo know-how, pela facilidade de acesso à matéria-prima estratégica e pela adequada localização geográfica, com vistas em produzir vantagens de custo.

As empresas também podem obter vantagens com o apoio diferenciado das regulamentações governamentais, criando barreiras à entrada de novas empresas na indústria. No caso do segmento madeireiro, a legislação florestal (criação de reservas extrativistas, planos de manejo), a legislação trabalhista e tributária, as tarifas e salvaguardas e o direito de propriedade constituem fortes barreiras à entrada de novas empresas.

Rivalidade: A segunda fonte de ameaça surge da ação de empresas rivais e ocorre quando é intensa a competição entre as empresas diretamente concorrentes, porque a forte concorrência tende a reduzir os lucros, em razão da diminuição forçada dos preços. Assim, grande número de fornecedores e de clientes de uma indústria pode levar a uma intensa rivalidade por parte das empresas concorrentes. A rivalidade tende a ser alta quando a taxa de crescimento da indústria for baixa. No caso da indústria madeireira, as empresas de madeira serrada e beneficiada enquadram-se nesse perfil, pois, na busca de manter e, ou, ampliar o market share, muitas empresas não conseguiram sobreviver e fecharam, enquanto outras passaram a operar na informalidade, por não suportarem a concorrência. 
Substitutos: A terceira fonte de ameaças é determinada pelos substitutos, que constituem uma ameaça quando os produtos ou serviços oferecidos pelas empresas rivais são considerados substitutos pelos clientes. Nesse caso, a empresa fica vulnerável às alterações nos preços dos produtos substitutos, que podem afetar diretamente sua rentabilidade. Na indústria madeireira isto ocorre porque a diferenciação de produtos é pequena e a qualidade é baixa, principalmente na indústria de madeira serrada e beneficiada.

Poder dos fornecedores: A quarta ameaça ao ambiente operacional da indústria é a condição de fatores ligados ao poder dos fornecedores. Os fornecedores podem ameaçar o desempenho das empresas de uma indústria, aumentando o preço ou diminuindo o padrão de qualidade da matéria-prima, principalmente quando há limitação de fatores. Essa prática tende a elevar os custos das empresas e a comprometer a sustentabilidade de suas rentabilidades. Assim, quando a empresa depende de um único fornecedor ou de um pequeno grupo de fornecedores e os produtos são altamente diferenciados, a empresa torna-se fortemente ameaçada por suas ações. No caso da indústria de madeira, é grande o número de fornecedores e o produto é homogêneo, entretanto, com a obrigação dos planos de manejo, as empresas já enfrentam dificuldade de obter matéria-prima legalizada, pois as áreas de manejo são insuficientes para a atividade industrial instalada. Com isso, muitas empresas de madeira serrada e beneficiada estão diminuindo a produção, enquanto outras fecharam.

Poder dos clientes: A quinta força ameaçadora do desempenho das empresas de uma indústria é a condição de demanda, dada pelo poder dos clientes. Da mesma forma que a ação dos fornecedores afeta o custo de produção, a ação dos clientes influencia a receita, diminuindo a rentabilidade da empresa. Um único cliente ou um grupo de poucos clientes, representando grande parcela das compras, pode ser uma poderosa ameaça, dada a pressão que podem fazer para baixar o preço e alongar os prazos de pagamento. Quando os produtos e, ou, serviços são padronizados, não-diferenciados e ofertados por várias empresas, há fortes 
ameaças de substituição de compras. Isso se torna mais preocupante quando as vendas desse produto representam uma grande parte dos custos dos clientes, o que não é o caso da madeira.

Em síntese, o modelo de cinco forças apresenta duas importantes implicações para que os gestores de empresas façam suas escolhas e implementem suas estratégias de gestão ou de governança das cadeias de suprimento. A primeira é que o modelo, de forma simples e flexível, permite descrever e avaliar as principais fontes de ameaça e oportunidade para o desempenho das empresas na indústria; a segunda e última é que o modelo pode ser utilizado na antecipação do desempenho médio das empresas de uma indústria.

O modelo das $\boldsymbol{F} \boldsymbol{C P}$, ao mesmo tempo que apresenta um conjunto importante de forças que ameaçam o desempenho das empresas, abre espaço para que sejam descritas algumas oportunidades destinadas à escolha de estratégias que possam neutralizar as ameaças. Tais oportunidades podem ser aproveitadas, caso o ambiente interno das empresas apresente saldo positivo entre os pontos fortes e suas fraquezas, que, no caso da madeira, são encontrados na dotação de fatores (matéria-prima, mãode-obra, infra-estrutura) e na ampla demanda dos produtos.

\subsubsection{Competitividade sistêmica}

A competitividade sistêmica vai além da análise tradicional que centrava esforço apenas na determinação e comparação de custos e na eficiência econômica. A análise de custo não perdeu importância para a análise da competitividade, porém outros fatores dinâmicos ganharam fôlego diante do contexto econômico global, em que se torna cada vez mais acirrada a concorrência por informação, por tecnologia e por idéias na disputa do mercado atual e na conquista de novos mercados. Na visão tradicional, a competitividade diz respeito ao esforço realizado pelas empresas para continuarem no mercado, mantendo e, ou, ampliando sua parcela de mercado (market share). 
O conceito de competitividade sistêmica adiciona a isso a influência de fatores, como infra-estrutura, política, tecnologia e instituições que atuam em toda a cadeia de negócios, e a dinâmica do mercado em tempo presente e futuro. Assim, a abordagem sistêmica da competitividade pode ser considerada como uma paisagem que se move ao sabor das influências das variáveis macroeconômica, institucionais, microeconômicas e de políticas, cujo resultado se traduz na criação de vantagens competitivas necessárias para criar, manter e, ou, ampliar seu market share (Santana, 2001).

A competitividade sistêmica constitui o marco de referência tanto para os países industrializados quanto para as economias em desenvolvimento, no que tange à análise da competitividade industrial. Esse conceito foi construído nas recentes discussões da Organização de Cooperação e Desenvolvimento Econômico (OCDE, 1992) e há dois elementos que o distinguem de outras abordagens que tratam também da competitividade industrial (Santana, 2000), a saber:

a) Esse conceito separa a análise em quatro níveis de abrangência: metanível, macronível, mesonível e micronível (Figura 1). Os níveis meta e meso são adicionados aos níveis micro e macro, que, geralmente, são considerados nas abordagens alternativas sobre competitividade. No metanível estão localizados fatores como capacidade de integração social e de estratégias que definem o padrão de governança. O mesonível, por sua vez, trata da estrutura das políticas que encorajam, suplementam e incrementam o esforço da atividade industrial;

b) O conceito de competitividade sistêmica conduz a análise para uma associação dos elementos da inovação tecnológica no âmbito da indústria, economia e sociologia industrial, destinada ao estudo das características e dos padrões de governança e dos fenômenos que resultam da interação da rede de cooperação e de alianças em torno das políticas industriais que atuam nas esferas social e institucional.

Para incrementar a competitividade e construir as vantagens competitivas, esforços devem ser direcionados, antes de tudo, para o âmbito da 
indústria, mesmo que a competitividade internacional das empresas não seja explicada apenas por abordagens restritas ao âmbito individual da empresa. As empresas, então, tornam-se competitivas quando as duas precondições seguintes são atendidas (Santana, 2002).

(a) Conviver com uma pressão competitiva que leva as empresas, continuamente, a envidarem esforços cada vez maiores para diferenciar produtos e elevar a eficiência dos processos de produção. Essa condição, de modo geral, não é atendida nas economias em desenvolvimento, sobretudo na Amazônia, onde o processo de industrialização ainda se inicia.

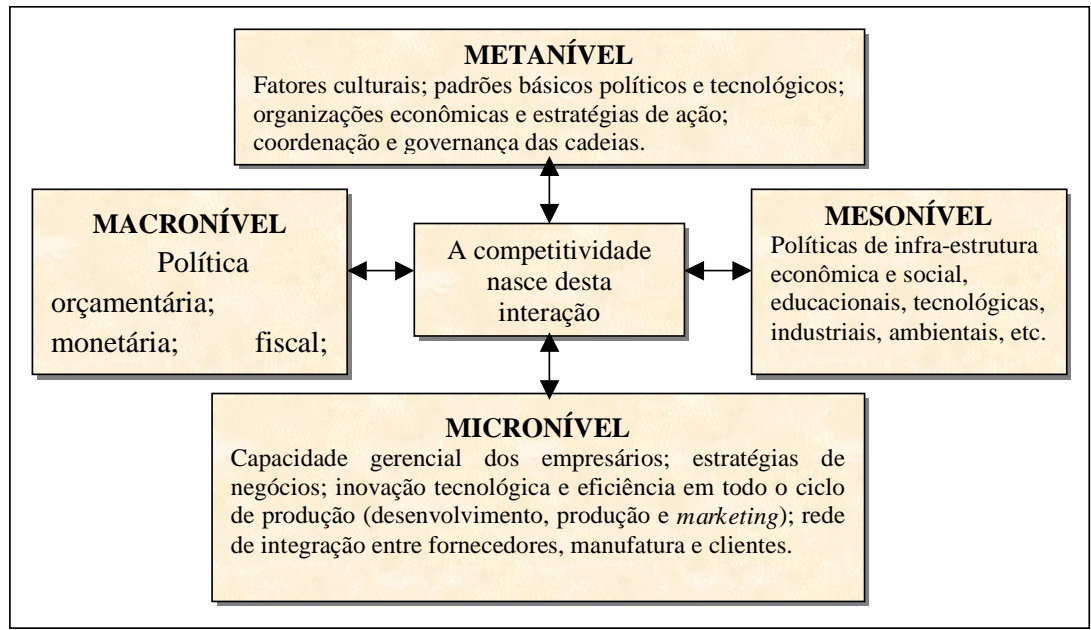

Figura 1 - Fatores determinantes da competitividade sistêmica.

(b) Estar preparado para a integração numa rede de empresas em que a variedade de externalidade, de serviço e de suporte institucional para a empresa é grande. Essa condição não tem sido orientada, de forma adequada, nas discussões e no desenvolvimento de políticas. Os ajustamentos, via de regra, ocorrem nos níveis micro e macro. Neste último, têm-se a estabilização (diga-se controle dainflação) e a administração do câmbio, que são empregados para corrigir vieses na estrutura de incentivos e estímulos aos empreendimentos nos níveis micro e meso. 
Numa visão de competitividade sistêmica, não se deve eleger, aleatoriamente, uma política individual ou apenas elementos isolados dentro do conjunto de determinantes da competitividade sistêmica (Figura 1) e adotálos como a política ideal para criar vantagens competitivas (Esser et al., 1999). Particularmente, as economias desenvolvidas têm estruturas no metanível que encorajam a competitividade, dispõem de uma macroestrutura que pressiona a performance das empresas, de uma organização no mesonível estruturada para abrigar as instituições e os atores sociais que, em conjunto, definem o suporte de políticas, e de grande número de empresas no micronível, estritamente organizadas e imbuídas para obter eficiência, qualidade, flexibilidade e agilidade, além de muitas outras que já se encontram conectadas em rede de cooperação e outras alianças competitivas. Ao resultado da interação simultânea e intertemporal desse conjunto de forças pode-se atribuir a denominação de competitividade sistêmica.

\section{Resultados e discussão}

A área de estudo é o Estado do Pará, considerando-se os pólos produtivos de Ananindeua, Belém, Breves, Marabá, Paragominas e Santarém. A escolha desses pólos madeireiros deve-se à sua representatividade em concentração industrial e em volume de produção e exportação dos produtos de madeira beneficiada e artefatos.

Neste trabalho foram consideradas informações resultantes de entrevistas em profundidade, realizadas nas empresas informais com potencial de crescimento e nas empresas líderes, e de dados obtidos da aplicação de questionários a uma amostra representativa de 266 empresas de madeira beneficiada do Estado do Pará (Santana, 2002). 


\subsection{Aspectos gerais das empresas de madeira beneficiada}

As empresas de madeira beneficiada respondem pelo maior contingente de empregos, estimado em cerca de 22.131 - e pelo maior valor exportado - em torno dos 186 milhões de dólares em 1998, o que representa $42,94 \%$ do total das exportações madeireiras (Santana, 2002). Em 2000, dos US\$313,11 milhões exportados pelo estado do Pará, cerca de 69,41\% (US\$ 217,41 milhões) foi de madeira serrada; $23,66 \%$ (US\$ 74,08 milhões), de compensado; 3,01\% (US\$ 9,41 milhões), de móveis; 2,59\% (US\$ 8,12 milhões), de laminado de madeira; e 1,33\% (US\$ 4,15\%), de artefatos de madeira. Todavia, foram estas as empresas mais atingidas pela valorização do câmbio, no período de 1994 a 1998, durante o Plano Real, pelas exigências da legislação ambiental, que proibia a exploração de algumas espécies de madeira em processo de extinção (mogno, ipê, cedro), exigindo manejo sustentável e ampliando a fiscalização nas empresas e no trânsito da madeira, pela insuficiente infra-estrutura de estradas e pelo encolhimento do mercado. Conseqüentemente, assistiramse ao fechamento de empresas e à redução da atividade produtiva em todos os pólos produtivos do Estado do Pará.

As empresas de madeira serrada e beneficiada apresentam uma estrutura de mercado desconcentrada, uma vez que a Taxa de Concentração de Mercado (TCM) e o Índice de Concentração de Herfindahl-Hirschman - IHH $\left(^{2}\right)$ são, respectivamente, da ordem de $39,69 \%$ e 421,8, o que assegura a existência de um padrão de concorrência pura (Santana, 2000 e 2002). Isso significa que a indústria madeireira (no que concerne às empresas de madeira serrada e beneficiada) oferece fraca barreira à entrada, uma vez que a concorrência se dá, principalmente, na base dos preços do produto e da matéria-prima.

\footnotetext{
${ }^{2}$ A Taxa de Concentração de Mercado (TCM) é a soma da parcela de mercado (PM) das cinco maiores empresas da indústria madeireira, dada pela fórmula TCM $=\Sigma_{(i=l}{ }_{5} \mathrm{PMi}$, e o índice de Herfindahl-Hirschman - IHH é dado pela soma do quadrado da parcela de mercado de cada empresa, calculado como IHH $=\sum_{(\mathrm{i}=1, \ldots, \mathrm{n})} \mathrm{PMi} 2$ (Santana, 2002).
} 
A matéria-prima encontrada com maior freqüência nas empresas é constituída das seguintes espécies de madeira: amesclão, angelim, assacu, caferana, caju, cedro, cedrorama, cerejeira, copaíba, curupixá, freijó, goiabão, ipê, jatobá, louro, marupá, maçaranduba, mogno, mulateiro, muriacatiara, para-pará, pau-amarelo, tauari, tatajuba, timborana, ucuuba, virola, axixá.

Os principais produtos de madeira beneficiada são tábuas serradas e, ou, beneficiadas (de madeira verde, seca ao sol e seca em estufa), barrotes de madeira em várias bitolas, pranchas e blocos de madeira serrada e, ou, beneficiada, sobras para ripado e caibro de casas e lenha para padarias. A madeira beneficiada (tábuas e barrotes secos em estufa) é destinada, segundo a bitola, às empresas de artefatos diversos (cabos de ferramentas, lambris, esquadrias, frisos, decks, peças para móveis, etc.), às movelarias de madeira densa, às empresas da construção de casas e peças para montagem de casas pré-fabricadas, exportadas para os mercados da União Européia e para os Estados Unidos, madeira para cercas divisórias de pastagens, estábulos e armazéns para estocar insumos.

A diferenciação do produto atende a dois diferentes padrões de qualidade, e a fabricação também é realizada de duas maneiras. Para o mercado externo, a matéria-prima constitui-se apenas de madeira nobre, porque se exige elevado padrão de qualidade, inclusive com tratamento químico para exterminar insetos e fungos, o que contribui para diminuir o aproveitamento da madeira, pois, de acordo com as empresas visitadas, o rendimento chega a ser de apenas 25 a 30\%, 4 a $3 \mathrm{~m}^{3}$ de madeira em tora para cada $1 \mathrm{~m}^{3}$ de madeira beneficiada, ou seja, madeira serrada, aplainada e cortada nas bitolas especificadas e sem defeitos. Para atender a tais requisitos de qualidade, após a serragem, a madeira é seca em estufas e envenenada para permitir o acabamento de primeira e evitar o ataque de insetos e fungos. As estufas fazem a diferença na qualidade do produto final, porque permitem a fabricação de produtos em menor tempo e conferem maior flexibilidade ao processo produtivo, em relação às empresas que secam madeira ao sol, sobretudo no período das chuvas, o que resulta em maior custo, baixa qualidade relativa dos produtos e menor capacidade para atender prontamente às mudanças na demanda. 
No produto destinado ao mercado interno, considerando-se o mesmo tipo de madeira, o nível de acabamento não atinge a qualidade total, dado que o mercado aceita pequenos defeitos no produto final. Com isso, o rendimento médio gira ao redor dos $40 \%$, ou seja, $2,5 \mathrm{~m}^{3}$ de madeira em tora para cada $1 \mathrm{~m}^{3}$ de madeira beneficiada.

O mercado local e, ou, regional, por sua vez, absorve um produto sem padrão de qualidade definido. Boa parte da produção destinada a esse mercado é constituída de madeira menos nobre, muitas delas não conhecidas no mercado internacional, do refugo de madeira nobre que, por defeito ou bitola diferenciada, não pode ser exportada e de aparas e sobras dos produtos comercializados no mercado externo ou nacional (abastece as empresas de artefatos, marcenarias, padarias, etc). As empresas que abastecem esse mercado são, geralmente, microempresas informais que trabalham com madeira verde, o que confere baixa qualidade ao produto, que corre o risco de empenar com o passar do tempo, uma realidade presente.

Nos mercados nacional e regional também há aproveitamento de outras madeiras nobres de menor valor comercial, em razão da abundância, que ainda é grande. $\mathrm{O}$ mercado é embrionário no que diz respeito à produção de alto valor agregado, pois a oferta local volta-se para atender ao consumidor de baixa renda. Os segmentos de renda média e alta adquirem produtos finais importados das regiões Sul e Sudeste, fabricados com madeira da Amazônia e comercializados nas lojas de mobiliário ou de representações comerciais do Sul e do Sudeste do País.

As empresas pesquisadas, principalmente as micro e pequenas empresas, em todos os pólos produtores do Estado do Pará revelaram que os fatores limitantes atuais são a carga tributária, a fiscalização acirrada do Ibama e a ausência de linhas de financiamento para capital de giro a juros compatíveis com a capacidade de retorno da atividade. No caso específico das microempresas de madeira beneficiada e algumas de artefatos, um fator que está causando grande preocupação é a concorrência desleal praticada pelas empresas informais, que não pagam impostos e comercializam produtos similares a preços mais baixos, porém sem garantia de qualidade. 


\subsection{Forças influenciadoras da competitividade}

Relação com fornecedores: As empresas de madeira serrada e beneficiada do Estado do Pará ainda não operam com contratos formais (contratos clássicos) de integração com os extratores. O que há é um relacionamento de confiança estabelecido entre as partes também denominado de contrato implícito, pois o mecanismo de exigibilidade é entre as próprias partes e os termos do relacionamento não são escritos. As partes estão convencidas de que estão participando de um jogo repetido, o que tende a diminuir a prática de oportunismo de ambas as partes. Isso significa que os custos de transação são baixos, dada a abundância de madeira da região das ilhas e em terra firme.

Das 266 empresas entrevistadas, 57,44\% responderam que, atualmente, adquirem madeira de áreas próprias e de áreas de pequenos extratores e $36,9 \%$ fazem extrativismo puro. Os demais insumos são adquiridos de empresas do mercado atacadista $(31,4 \%)$, varejista $(29,3 \%)$ e de outras indústrias $(24,7 \%)$.

A madeira, em grande parte, é adquirida de pequenos extratores e de áreas arrendadas para extração de madeira. Poucas empresas possuem áreas próprias e fazem manejo sustentável ou reflorestamento. No Estado do Pará, apenas duas empresas receberam o "selo verde", e outras empresas de grande porte estão em processo adiantado para conseguir o certificado internacional da série ISO 14000. O "selo verde" ou certificação florestal confere à empresa uma marca de confiabilidade e segurança, dando garantia à sociedade de que a madeira utilizada no processo industrial é oriunda de floresta manejada de forma sustentada, ou seja, segundo a orientação ecologicamente correta, economicamente viável e socialmente justa.

Há consciência de que o manejo se transformou em pressuposto para as empresas madeireiras. Como essa prática passou a ser obrigatória, muitas empresas de médio e grande porte fecharam (nos pólos de Marabá, Paragominas e Santarém), e outras estão operando com grande capacidade ociosa, o que reduz a rentabilidade da empresa. Todavia, outras 
empresas ajustaram seu tamanho e investiram na agregação de valor e na diversificação dos produtos.

A demora do Ibama para analisar e aprovar projetos de manejo e conceder a autorização para que a extração seja realizada nos talhões, segundo relato dos empresários, está afetando o cronograma de produção das empresas. Geralmente, decorrem, aproximadamente, dois meses entre a solicitação e a posterior liberação da extração nos talhões. Em razão disso, a maioria das serrarias está adquirindo madeira de pequenos extratores e intermediários.

Finalmente, as relações com os fornecedores, sobretudo com os pequenos extratores e proprietários de áreas de "projetos de manejo", consolidam-se com o emprego da tática de pagamento antecipado de uma parcela do valor da compra; em alguns casos, as empresas concedem financiamento antecipado em troca do pagamento em madeira, fazendo o papel do sistema financeiro. Além da ausência de linhas específicas de crédito para essa atividade, os juros das linhas existentes são proibitivos, o que vincula mais fortemente os fornecedores de madeira ao segmento de serrarias, laminados e compensados. São exatamente esses pontos que permitem criar e manter a sustentabilidade das vantagens competitivas nessa atividade produtiva.

Relação com clientes: As relações com os clientes também não exigem contratos formais. Todas as empresas visitadas atendem às demandas, por encomenda, de clientes novos e antigos. Mesmo para as madeiras nobres, não há problemas de mercado. Atualmente, a produção de um conjunto de empresas dos pólos produtores de Belém, Ananindeua, Marabá, Breves, Santarém e Paragominas destinam-se aos mercados das regiões Nordeste (em torno de 65 a 70\%), Sudeste e Sul (de 25 a $20 \%$ ), e o restante, ao mercado local. Nesses pólos, estão também instaladas as mais representativas empresas que exportam madeira beneficiada, cuja proporção é de $70 \%$ para os mercados do Sudeste e Sul do Brasil e cerca de 30\% para os Estados Unidos, países do Mercosul e da União Européia, principalmente. O setor não investe em pesquisa, propaganda e marketing para adequar sua oferta, mas age com base nas 
exigências dos clientes e, quando há coisa nova, procuram superar o desconhecimento e atender aos pedidos.

$\mathrm{Na}$ cadeia produtiva de madeira beneficiada para os mercados regional e nacional, há vários intermediários até o produto chegar ao consumidor final. Um desses intermediários são as estâncias de material de construção. As vendas são, geralmente, efetivadas a prazo.

As relações são estabelecidas, principalmente, com empresas do mercado atacadista $(24,6 \%)$, mercado varejista $(21,1 \%)$, empresa exportadora $(20,2 \%)$ e consumidor final $(17,6 \%)$. As relações ocorrem na forma de subcontratação $(47,8 \%)$ e de contratos eventuais $(34,8 \%)$ pelos clientes. Apenas em 17,4\% dos casos, as empresas são contratadas para fornecer produtos acabados. Os principais fatores levados em conta na escolha do produto são preço $(31,3 \%)$, qualidade $(28,9 \%)$, condições de pagamento $(15,3 \%)$ e pontualidade na entrega $(12,4 \%)$.

Tecnologia e informação: No que diz respeito à tecnologia, há defasagem de máquinas e equipamentos utilizados; nesse aspecto, não há diferença substancial entre as empresas. Predomina o uso de serras de fita nacionais para madeira grossa e de máquinas de aplainar e alisar madeira. As máquinas têm de 5 a 10 anos de uso (28,9\%); algumas empresas possuem máquinas com menos de 5 anos de uso $(32,11 \%)$.

As empresas podem ser diferenciadas em função de ativos estratégicos. Por um lado, há as que possuem estufas para secar madeira, obtendo, com isso, maior qualidade do produto beneficiado, maior rendimento da mãode-obra e facilidade no acabamento. Por outro, há serrarias que, por falta de capital, trabalham com madeira verde, sujeitando-se a perdas por causa do empenamento das tábuas quando secas ao sol e do ataque de insetos e fungos; além disso, o tempo de processamento aumenta e o produto final é de qualidade inferior. Isto implica baixa capacidade para reagir prontamente às encomendas de empresas que atendem aos segmentos de consumidores com maior poder aquisitivo. Por isso, investir na aquisição de estufas é o anseio das serrarias em atividade, mas faltam linhas de financiamentos, a juros suportáveis, para a atividade. 
Com relação à tecnologia da informação e do conhecimento, apenas $17,7 \%$ empregam computador e Internet na venda e $14,3 \%$, no processo de produção; as demais fazem uso de computador apenas na contabilidade. As informações que mais interessam aos empresários da madeira, embora não-sistemáticas, envolvem os concorrentes locais $(20,4 \%)$, os fornecedores locais $(15,2 \%)$, os clientes locais $(10,4 \%)$, os clientes nacionais e internacionais $(15,4 \%)$ e $13,8 \%$ não dispõem de nenhuma informação. Observa-se que a preocupação dos empresários é com o mercado local, que absorve cerca de $29,32 \%$ da produção de madeira serrada e beneficiada. O mercado nacional compra cerca de $43,71 \%$ da produção. A exportação é realizada, principalmente, para a União Européia (30,0\%), Nafta (25,9\%), Bloco Asiático (18,2\%), Caribe (12,5) e Mercosul $(8,8 \%)$.

Quanto ao controle de qualidade da produção, 71,4\% realizam-no em todo o processo; em relação à aquisição de insumos, 59,8\% controlam a entrega e $25,9 \%$ não fazem controle de qualidade. Apenas $47 \%$ das empresas utilizam normas técnicas (ISO ou NBR).

Mão-de-obra: A mão-de-obra é treinada na própria empresa, processo este demorado, visto que se aproveitam as horas de folga dos funcionários mais experientes, que se dispõem a ensinar seu ofício para aqueles que se destacam e se interessam em aprender a profissão de operador de máquinas, serralheiro, marceneiro, etc. A mão-de-obra de qualidade (treinada e capaz de trabalhar em grupo e assumir responsabilidade na condução do processo produtivo), segundo resposta de quase $95 \%$ das empresas entrevistadas, praticamente não existe no mercado regional.

Atualmente, os principais critérios de seleção de empregados pelas 266 empresas são a experiência profissional $(42,4 \%)$ e a indicação $(21,0 \%)$. As principais áreas de treinamento da mão-de-obra são segurança e medicina do trabalho $(25,5 \%)$, operações de máquinas e equipamentos $(21,6 \%)$, qualidade e produtividade $(10,4 \%)$, qualidade ambiental $(6,3)$ e tecnologia de produção $(3,9 \%)$. 
Preço do produto: O preço de venda dos produtos é determinado com base no custo total médio de produção (na realidade, muitos dos entrevistados consideraram apenas o custo variável médio), e, de acordo com as regras do mercado e as estratégias dos concorrentes, adiciona-se uma margem de lucro a esse nível de custo. Muitos empresários revelaram que, em algumas espécies de madeira, apenas empatam os custos e, em outras, têm prejuízo porque o rendimento da madeira é muito baixo (entre 25 e $30 \%$ ).

$\mathrm{Na}$ determinação do preço, todas as empresas procuram informações sobre o mercado, que envolve concorrentes, fornecedores e clientes, para estabelecer suas margens de lucro e conduzir suas ações.

Os principais itens de custo que influenciam a determinação do preço e lucratividade são matéria-prima (madeira - 27,2\%), mão-de-obra $(17,5 \%)$ e impostos e taxas $(14,7 \%)$.

O preço é uma variável de grande impacto na competitividade, pois, mesmo para um produto aparentemente homogêneo aos olhos do consumidor, as empresas, dados os seus níveis de custo médio totais, ajustam suas margens para oferecer preço mais competitivo ao cliente. Associadas ao preço, há as diferenças nos padrões de qualidade e as externalidades criadas por meio do pronto atendimento e do aproveitamento dos efeitos produzidos pelas demais variáveis influenciadoras das preferências do consumidor.

Organização e estratégias: A organização das empresas em cooperativas ou condomínios é um pressuposto fundamental para criar as economias de aglomeração, resultado direto das estratégias corporativas e cooperativas. Essa é a força motora dos agrupamentos produtivos sistêmicos, uma vez que a simples força das estratégias competitivas (liderança de custo e diferenciação de produtos) não representa uma condição de suficiência para a competitividade sistêmica.

Com respeito à organização das empresas, apenas 58,7\% participam de algum tipo de organização (sindicatos, associações de classe, cooperati- 
vas, etc.). Quanto às técnicas de organização da produção, apenas 17,7\% fazem rodízio e polivalência nos postos de trabalho; $10,5 \%$ têm círculos de controle de qualidade; $6 \%$ têm células de produção; e $4,1 \%$ realizam o controle estatístico de processos.

Apesar desse embrião organizativo, não existe na indústria madeireira do Estado do Pará uma cultura estabelecida para a troca de experiências tecnológicas de produto e processo. Em razão disso, o diferencial tecnológico se dá pela própria capacidade de gestão das empresas e pela versatilidade de ação. Todavia, foi evidenciado que os empresários, além das demandas dos clientes, realizam viagens técnicas pelos principais centros de produção e de consumo para, então, ajustar a produção à dinâmica do consumo.

Fatores institucionais: $\mathrm{O}$ apoio institucional à atividade madeireira no Estado do Pará é desarticulado e pouco contribui para a dinâmica das relações de negócios entre os empresários. Em vez de cooperar, as instituições são apontadas como criadoras de limitações ao desempenho empresarial. Entre os fatores que ameaçam o desenvolvimento destas, foram apontadas, em primeiro lugar, a carga tributária pesada e a legislação ambiental.

Com relação às linhas de crédito, constatou-se a existência de generalizado descontentamento com a dinâmica do segmento madeireiro, pois, apesar do giro rápido, não se dispõe de linhas de crédito com juros compatíveis com a capacidade de retorno para capital de giro e para investimento. Além dos juros elevados $(26,1 \%)$, os encargos financeiros $(20,2 \%)$, as exigências de garantias $(16,4 \%)$, os prazos inadequados $(16,7 \%)$ e o excesso de burocracia acabam afastando os empresários da captação das linhas de crédito existentes. Em virtude disso, apenas 16,9\% e 14,7\% das 266 empresas entrevistadas, respectivamente, tinham crédito de curto e longo prazos.

A assistência técnica é um ponto fundamental para orientar os planos de manejo florestal junto aos produtores rurais e para supri-los de conhecimentos técnicos em gestão de empresas, avaliação e controle dos fluxos 
de caixa das empresas, tratamento de informações e tomada de decisão, treinamento de mão-de-obra e capacitação técnica.

Das 266 empresas entrevistadas, apenas 13,9\% recebiam assistência técnica ou gerencial. As principais dificuldades de acesso aos serviços de assistência técnica citadas foram: grandes distâncias entre os centros de apoio e as empresas $(27,8 \%)$ e desconhecimento dos serviços disponíveis $(26,8 \%)$. Muitas empresas simplesmente não procuram os serviços $(17,5 \%)$.

Instrumentos de política econômica: A estabilização da economia brasileira é o principal ponto para apoiar a competitividade empresarial, porque construiu um ambiente de planejamento. No âmbito interno, a variável de maior influência na indústria madeireira foi o crescimento da economia brasileira, conforme Santana (2002).

Com relação às exportações, o câmbio foi a variável de maior impacto no desempenho da atividade madeireira do Estado do Pará (Santana, 2002). Nas empresas exportadoras, o impacto é direto; e nas empresas voltadas para o mercado nacional, indireto. O câmbio sobrevalorizado, como no período 1994/1998, desaquece o mercado exportador porque o segmento está indexado ao dólar. No câmbio desvalorizado, como ocorreu no início de 1999, os extratores refazem seus cálculos e, ao vislumbrarem margem positiva de lucro, ampliam o raio de exploração e passam a ofertar mais madeira, dado que os preços compensam os custos de extração e de transporte em maiores distâncias. Os principais fatores desfavoráveis às exportações são aduana e licenciamento (49,3\%), burocracia excessiva $(15,9 \%)$, falta de financiamento $(14,4 \%)$ e custos portuários $(9,4 \%)$, segundo 266 empresas entrevistadas. Os pontos fortes são preço $(23,7 \%)$ e qualidade do produto $(21,4 \%)$. 


\section{Considerações finais}

O eixo central da análise de competitividade está na estruturação da cadeia produtiva, que abrange as articulações das empresas de madeira beneficiada com os fornecedores e clientes. As relações para trás, estabelecidas com os fornecedores de madeira, estão mudando completamente, visto que os empresários estão implementando planos de manejo em suas áreas de extração e orientando os pequenos extratores para que implementem também o manejo de baixo impacto. Cerca de $37 \%$ das empresas que realizam extrativismo puro está fora do mercado, em razão da fiscalização ambiental, que proíbe essa prática. Muitas empresas de médio e grande porte fecharam e outras estão sendo autuadas por causa desse ato ilícito. Ao final, vão permanecer em atividade apenas as empresas que cumprem as legislações ambiental, trabalhista e tributária.

As ligações para frente estão se fortalecendo, e empresas estão sendo contratadas para fornecer matérias-primas nas várias bitolas e diferenciações e outras para fornecer produtos finais. Com a diminuição do número de empresas e com o ajuste no tamanho e na organização produtiva, a tendência que se esboça é o estabelecimento de alianças estratégicas entre empresas, fornecedores e clientes, o que culmina em contratos para a entrega regular de matéria-prima e, principalmente, de produtos intermediários e finais.

No âmbito interno das empresas, mudanças estão se processando no emprego de tecnologia. Algumas empresas utilizam máquinas para serrar madeira fina e reduzir desperdícios, enquanto outras avançam no emprego de estufa para secar madeira, na aquisição de máquinas de beneficiamento de madeira para aumentar a qualidade e diferenciar o produto, ao produzir bitolas diferentes e iniciar a fabricação de peças, produtos finais e artefatos. Em torno dessa mudança, a qualificação da mão-de-obra passou a constar nas prioridades, assim como a utilização de mais informação sobre mercado, concorrentes, tendências de consumo e os requisitos legais. Tudo isso se alia aos novos métodos de gestão 
empresarial, dando maior flexibilidade e mobilidade no trato dos fatores estruturais, internos e sistêmicos do ambiente competitivo das empresas de madeira.

Com relação ao entorno das ações empresariais, observa-se tendência de formação de alianças competitivas, cooperativas e corporativas, que se inicia com a determinação das cadeias de custódias dos produtos não apenas por empresa, mas também por pólo produtor, para atender às tendências nacionais e internacionais do mercado consumidor.

Os fatores institucionais e de política econômica que envolvem linhas de crédito, legislação ambiental, trabalhista, infra-estrutura, tributação, entraves nas exportações e assistência técnica constituem pontos de ameaça de difícil equacionamento no curto prazo, mas que caminham para o equacionamento no médio e longo prazo. Os empresários já internalizaram tais fatores em suas metas, que se transformaram em grandes oportunidades.

Pelo que se observa da análise de resultados, os pontos fracos e as ameaças às empresas de madeira beneficiada superam os pontos fortes e as oportunidades no curto prazo, dado o processo histórico de exploração dos recursos naturais sem regra e dada a reestruturação radical por que passaram os processos e direitos de exploração da floresta amazônica. Tal reestruturação envolve não apenas a alteração na estrutura organizacional da indústria madeireira, mas também uma mudança de atitude empresarial.

As mudanças efetivaram-se na segunda metade dos anos 90 e caminham para a sua consolidação ainda nessa primeira década do século XXI. O resultado disso é que as empresas de madeira serrada e beneficiada sofreram o maior impacto da indústria madeireira, em razão da legislação ambiental e da pressão internacional, que exigia o "selo verde", e experimentaram uma perda de competitividade internacional muito forte entre 1995 e 2001 , tendo o market share reduzido de $65,55 \%$, em 1995, para 51,93\%, em 2001. 


\section{Referências Bibliográficas}

BAIN, J.S. Industrial organization. 2 ed. New York: Wiley, 1968.

BARNEY, J.B. Gaining and sustaining competitive advantage. New York: Addison-Wesley Publishing Company, 1997.

COUTINHO, L., FERRAZ, J.C. (coord.) Estudo da competitividade da indústria brasileira. 2 ed. Campinas: Papirus, 1994.

ESSER, K.; HILLEBRAND, W.; MESSNER, D.; MEYER-STANNER, J. Systemic competitiveness - new challenges to business and politics. Economics, v.59, 1999.

MASON, E.S. Price and production policies of large scale enterprises. American Economic Review, v.29, n,1, p.61-74, 1939.

OCDE. Technology and the economy. The key relationiships. Paris: 1992.

PORTER, M.E. The competitive advantage of nations. New York: Free Press, 1990.

POSSAS, M.L. Competitividade: fatores sistêmicos e política industrial - implicações para o Brasil. In: Castro, A.B. (org.), Possas, M.L. (org.), Proença, A. (org.) Estratégias empresariais na indústria brasileira: discutindo mudanças. Rio de Janeiro: Forence, 1996. P.71-117.

POSSAS, M.L. Estrutura de mercado em oligopólio. 2 ed. São Paulo: Hucitec, 1987.

SANTANA, A.C. de A competitividade sistêmica das empresas de madeira na Região Norte. Belém: M\&S Editora, 2002.

SANTANA, A.C. de A competitividade das micro e pequenas empresas de madeira beneficiada e artefatos da Região Norte. São Paulo: Macrotempo; Sebrae, 2000. (Relatório de Pesquisa) 
SANTANA, A.C. de A economia do Pará e as perspectivas de crescimento. MONTEIRO, W. (org.) Guia Empresarial do Pará. Belém, 2001, V. Único, p.90-99.

SUZIGAN, W., FURTADO, J., GARCIA, R., SAMPAIO, S.E.K. Aglomerações industriais no Estado de São Paulo. Economia Aplicada, v.5, n.4, p.698-717, out./dez. 2001. 